\title{
CARACTERÍSTICAS AGRONÔMICAS E PRODUTIVAS DA SOJA CULTIVADA EM PLANTIO CONVENCIONAL E CRUZADO
}

\author{
Fabrício Ribeiro Andrade ${ }^{1}$, Júlio César Azevedo Nóbrega ${ }^{2}$, Alan Mario Zuffo ${ }^{3}$, Valdir Prates \\ Martins Junior ${ }^{4}$, Tiago Pieta Rambo ${ }^{4}$, Adaniel Sousa dos Santos ${ }^{4}$
}

${ }^{1}$ Instituto Federal de Mato Grosso - IFMT, E-mail: fabricioandradeagro@gmail.com
${ }^{2}$ Universidade Federal do Recôncavo da Bahia - UFRB, E-mail: juliocnobrega@gmail.com
${ }^{3}$ Universidade Federal De Lavras - UFLA, E-mail: alan_zuffo@hotmail.com
${ }^{4}$ Universidade Federal do Piauí - UFPI, E-mail: valdir_prates@hotmail.com

RESUMO

Objetivou-se com o presente estudo avaliar o desenvolvimento e a produtividade de grãos na cultura da soja submetida a diferentes densidades de semeadura, em linhas de semeadura convencionais e cruzadas. Observou-se acréscimo na altura de inserção do primeiro legume de plantas cultivadas em elevadas densidades. As diferentes densidades de semeadura no sistema cruzado promoveram maior massa de mil grãos, embora isso não tenha se refletido em maior produtividade, apenas uma compensação do menor número de legumes por planta.

Palavras-chave: Glycine max, Densidade, Plantio

\section{AGRONOMIC AND PRODUCTIVE CHARACTERISTICS OF SOYBEAN CULTIVATED UNDER CONVENTIONAL AND CROSS SEEDING SYSTEMS}

\begin{abstract}
The aim of this study was to evaluate the development and grain yield of soybean cultivated under different sowing densities, on conventional and cross seeding systems. There was an increase in the height of the first pod insertion, when high densities were adopted. The different densities on the cross seeding system promoted a higher thousand grain mass although not showing higher yield, being only a compensation because of the lower number of pods per plant.
\end{abstract}

Keywords: Glycine max, Density, Sowing

\section{INTRODUÇÃO}

O cultivo da soja [Glycine max (L.) Merrill] é um dos mais importantes no Cerrado piauiense, região que vem se destacando no cenário nacional pelo grande potencial na produção de grãos (PETTER et al., 2012). Segundo a Companhia Nacional de Abastecimento - CONAB (2014), na safra 


\section{CARACTERÍSTICAS AGRONÔMICAS E PRODUTIVAS DA SOJA CULTIVADA EM PLANTIO \\ CONVENCIONAL E CRUZADO}

2013/14, a área cultivada com soja no estado atingiu aproximadamente 627.300 ha, com rendimento médio de grãos de $2.374 \mathrm{~kg} \mathrm{ha}^{-1}$.

A sojicultora brasileira ao longo das últimas décadas tem passado por um intenso processo de expansão em que a produtividade, a eficiência, a lucratividade e a sustentabilidade econômica e ambiental são aspectos de grande relevância. Dessa forma, vem se buscando novas tecnologias com o objetivo de atender tais aspectos onde se destacam; manejo fitossanitário, melhorias da qualidade física, química e biológica do solo, cultivares transgênicas, genótipos com alta adaptabilidade, época adequada de semeadura e densidade populacional.

Nesse sentido, tem se adotado recentemente o plantio cruzado, com a finalidade de promover ganhos produtivos, principalmente nas áreas marginais de plantio, como uma forma compensatória. A semeadura cruzada consiste na distribuição de sementes em linhas paralelas, como é realizada convencionalmente na soja, seguida de nova distribuição de sementes sobre a mesma área, com as novas linhas formando ângulos de $90^{\circ}$ em relação às anteriores, ou seja, formando um gride de linhas sobre a área de cultivo (LIMA et al., 2012).
Diversos estudos abordam principalmente a densidade de semeadura na cultura da soja, definindo aquelas que melhor se ajustam para determinadas cultivares (FREITAS et al., 2010; MAUAD et al., 2010), no entanto, o arranjo espacial das plantas na área, em sistema de semeadura cruzada, ainda é restrito (LIMA et al., 2012; PROCÓPIO et al., 2013) e inexistem estudos a respeito desse sistema na região do Cerrado piauiense.

De acordo com Freitas et al. (2010) a interação entre a planta, o ambiente de produção e o manejo são preponderantes para definir a produtividade de uma cultura, dessa forma altos rendimentos são obtidos quando o genótipo apresenta potencial produtivo e alta adaptabilidade, tudo isso aliado aos tratos culturais requeridos pela cultura.

De acordo com Lima et al. (2012) alterações relacionadas com a população de plantas podem reduzir ou aumentar os ganhos produtivos, pois essa característica é consequência da densidade das plantas nas linhas e do seu espaçamento entre as linhas. A densidade de semeadura pode interferir na competição inter e intra-específica por recursos do solo, especialmente água e nutrientes, além de provocar mudanças morfofisiológicas nas plantas (ARGENTA et 
al., 2001), entretanto, a competição por fatores como luz, nutrientes e umidade do solo pode influenciar negativamente $\mathrm{o}$ processo de produção (TOURINO et al., 2002; WATANABE et al., 2005).

Tourino et al. (2002), trabalhando com variações no espaçamento entre linhas e diferentes densidades de plantas, verificaram que a produtividade da soja aumenta com a redução do espaçamento entre linhas aliado à redução da densidade de plantas nas linhas, tendo o espaçamento de $45 \mathrm{~cm}$ entre as linhas e densidade de 10 plantas $\mathrm{m}^{-1}$ proporcionado melhor distribuição das plantas na área e maior produtividade. Nesse sentido, Rambo et al. (2003), estudando as respostas produtivas da cultura da soja quanto a variação do espaçamento entre linhas e densidade de plantas, verificaram que o arranjo de plantas constituído pela combinação da população de 20 plantas $\mathrm{m}^{-2}$ e o espaçamento de $20 \mathrm{~cm}$ entre linhas foi o que apresentou a maior produtividade.

No desafio nacional do CESB (Comitê Estratégico Soja Brasil) na safra 2009/2010 o produtor vencedor alcançou a marca de 108,4 sacas de soja por hectare no Paraná, utilizando a semeadura da soja em linhas cruzadas, técnicas de manejo adequadas e contando com condições climáticas ideais; dessa forma o uso da semeadura da soja em linhas cruzadas pôde ser um indicativo do potencial de aumento da produtividade (CULTIVAR, 2010). Informações sobre o comportamento da soja em semeadura cruzada ainda são incipientes na literatura, se limitando ao estudo realizado em Chapadão do Sul, MS por Lima et al. (2012) e Procópio et al. (2013) em Londrina-PR; entretanto, as condições edafoclimáticas são variáveis entre as regiões, o que altera a reposta da cultura. Neste sentido, estudos que almejam verificar o potencial desse tipo de semeadura são fundamentais, uma vez que além de alterar a densidade de semeadura ocorre também uma mudança intensa no arranjo das plantas na área.

Diante desse contexto, objetivou-se com o presente estudo avaliar o desenvolvimento e produtividade de grãos na cultura da soja submetida a diferentes densidades de semeadura, em linhas de semeadura convencionais e cruzadas.

\section{MATERIAL E MÉTODOS}

O experimento foi realizado a campo na safra 2011/2012, na Fazenda União (Serra das Laranjeiras) localizada no município de Currais, PI cujas coordenadas pontuais são 08 $38^{\prime} 12^{\prime \prime}$ de latitude e 44\%40'11', de 


\section{CARACTERÍSTICAS AGRONÔMICAS E PRODUTIVAS DA SOJA CULTIVADA EM PLANTIO \\ CONVENCIONAL E CRUZADO}

longitude, com altitude média de $550 \mathrm{~m}$, solo classificado como Latossolo Amarelo distrófico - LAd, textura franco arenosa (argila: 160, silte: 50 e areia: $790 \mathrm{~g} \mathrm{~kg}^{-1}$ ), (Tabela 1). O histórico da área é caracterizado pelo cultivo em monocultura da soja desde o ano de 2004, recebendo aplicações anuais de $500 \mathrm{~kg} \mathrm{ha}^{-1} \mathrm{de}$ fertilizante 00-20-20 (N-P $\left.\mathrm{P}_{2}-\mathrm{O}_{2} \mathrm{O}\right)$.
O clima da região é do tipo Aw, segundo a classificação climática global de Köppen, com duas estações bem definidas, sendo uma seca (maio a setembro) e outra chuvosa (outubro a abril). Os dados de precipitação acumulada e temperatura média ocorrida durante a realização do experimento foram registrados (Figura 1).

Tabela 1. Composição química do Latossolo Amarelo distrófico $(0,00-0,20 \mathrm{~m})$ no local do experimento na região do Cerrado piauiense, Currais-PI, Brasil, safra 2011/2012.

\begin{tabular}{ccccccccccc}
\hline $\mathrm{pH}$ & $\mathrm{Ca}^{2+}$ & $\mathrm{Mg}^{2+}$ & $\mathrm{Al}^{3+}$ & $\mathrm{H}+\mathrm{Al}$ & $\mathrm{SB}$ & $\mathrm{CTC}$ & $\mathrm{P}$ & $\begin{array}{c}\mathrm{K}^{+} \\
\mathrm{MO}\end{array}$ & $\begin{array}{c}\mathrm{V} \\
\mathrm{CaCl}_{2}\end{array}$ \\
\hline 4,6 & 2,10 & 1,00 & 0,20 & 3,30 & 3,50 & 6,39 & 53,0 & 74,00 & 15,00 & 51,49
\end{tabular}

H + Al: acidez potencial; SB: soma de bases; CTC: capacidade de troca catiônica a pH 7,0; MO: matéria orgânica; V: saturação por bases.

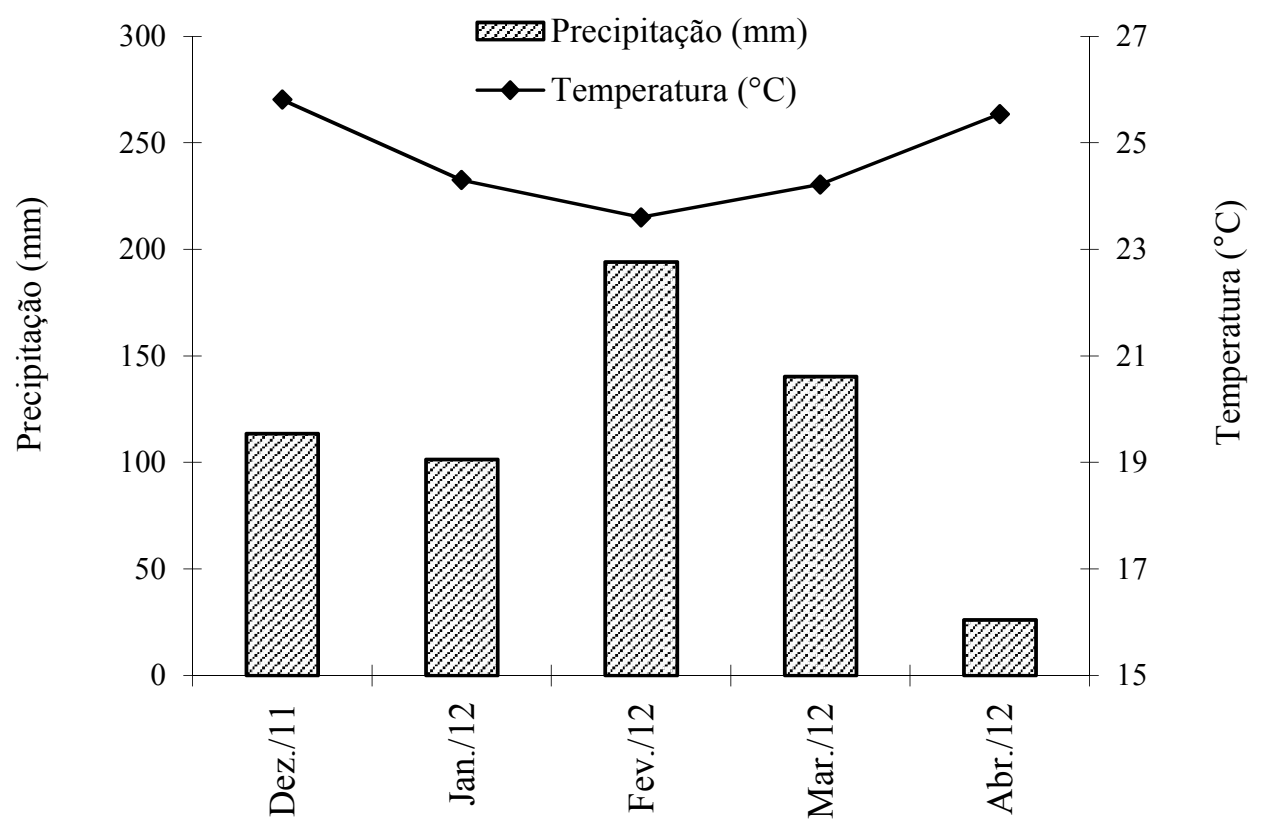

Figura 1. Temperatura média, umidade relativa e precipitação ocorrida na Fazenda União, situada no munícipio de Currais-PI durante o período de dezembro de 2011 a abril de 2012, na região de Cerrado piauiense. 
O delineamento experimental utilizado foi o de blocos ao acaso, com quatro repetições e oito tratamentos constituídos pelo plantio convencional e cruzado (Tabela 2). Cada parcela foi constituída por 5,5 $\mathrm{m}$ de comprimento e 5,5 de largura, com linhas de plantio espaçadas de $0,50 \mathrm{~m}$, tendo a área de cada parcela $30,25 \mathrm{~m}^{2}(5,5 \times 5,5 \mathrm{~m})$. Como área útil foram consideradas as três fileiras centrais, excluindo $1 \mathrm{~m}$ de cada extremidade.

A cultivar de soja utilizada no experimento foi a M-soy 9144 RR, considerada de ciclo tardio, hábito de crescimento determinado, recomendada para solos com fertilidade média a alta. As sementes foram tratadas com inseticida+fungicida (Standak Top ${ }^{\circledR}$ ) e na ocasião da semeadura as mesmas foram inoculadas com Bradyrhizobium japonicum, estirpes SEMIA 5079 e 5080. No ato da semeadura da soja, realizou-se a adubação na linha de plantio, aplicando $350 \mathrm{~kg} \mathrm{ha}^{-1} \mathrm{da}$ fórmula 00-24-12 (N- $\left.\mathrm{P}_{2} \mathrm{O}_{5}-\mathrm{K}_{2} \mathrm{O}\right)$. Ao atingir os estádios fenológico entre $\mathrm{V}_{4}$ e $\mathrm{V}_{5}$ realizou se a adubação potássica em cobertura a lanço aplicando $40 \mathrm{~kg} \mathrm{~K}_{2} \mathrm{O} \mathrm{ha}{ }^{-1}$. Durante todo o ciclo da cultura o controle de pragas foi realizado obedecendo aos níveis de controle e para o controle de doenças foi realizada aplicação de produtos preventivos à incidência, com os produtos recomendados para a cultura.

Tabela 2. Descrição dos tratamentos, sistemas de semeadura (convencional e cruzado), arranjo e população de plantas, Currais-PI, Brasil, safra 2011/2012.

\begin{tabular}{cccc}
\hline Trat. & Sem. & Arranjo & D. P. $\left(\mathrm{ha}^{-1}\right)$ \\
\hline T1 & P & 6 & 120.000 \\
T2 & P & 8 & 160.000 \\
T3 & P & 10 & 200.000 \\
T4 & P & 12 & 240.000 \\
T5 & C & $6 \times 6$ & 240.000 \\
T6 & C & $8 \times 8$ & 320.000 \\
T7 & C & $10 \times 4$ & 280.000 \\
T8 & C & $10 \times 10$ & 400.000 \\
\hline
\end{tabular}

Trat: tratamento; Sem: semeadura; arranjo; D.P: densidade de plantas; P: convencional; C: cruzado 


\section{CARACTERÍSTICAS AGRONÔMICAS E PRODUTIVAS DA SOJA CULTIVADA EM PLANTIO \\ CONVENCIONAL E CRUZADO}

Ao atingir o estágio fenológico $\mathrm{R}_{1}$, procedeu-se a mensuração da altura das plantas, fitomassa seca da parte aérea, teor relativo de clorofila $\mathrm{a}, \mathrm{b}$ e total. O teor relativo de clorofila, foi mensurado com clorofilômetro (clorofilLOG CFL 1030), sendo utilizado para amostragem o terceiro trifólio totalmente desenvolvido considerando do ápice para base (folha diagnóstico), amostrando-se três trifólios por parcela. A fitomassa seca da parte aérea foi obtida secando-se as plantas em estufa de ar com circulação forçada a $60^{\circ} \mathrm{C}$ por 72 horas e em seguida pesando-se em balança de precisão $(0,001 \mathrm{~g})$.

Ao final do ciclo da cultura foi realizada a coleta de cinco plantas para avaliar a altura de inserção do primeiro legume, número de legumes por planta e o número de grãos por legume. Posteriormente, coletaram-se manualmente as plantas contidas na área útil da parcela, que foram trilhadas mecanicamente e a produção transformada em $\mathrm{kg} \mathrm{ha}^{-1}$ de grãos, padronizado a $13 \%$ de umidade, sendo avaliada também a massa de mil grãos.

Para testar as diferenças entre os tratamentos efetuou-se uma análise de variância e no caso de haver significância $(\mathrm{p}<0,05)$, as médias das variáveis significativas foram agrupadas pelo critério de Scott-Knott a 5\% de significância, utilizando-se o programa estatístico Sisvar ${ }^{\circledR}$ (FERREIRA, 2011).

\section{RESULTADOS E DISCUSSÃO}

Independentemente do sistema de semeadura e densidade de plantas de soja, as clorofilas a, b e total, não foram significativamente influenciadas (Tabela 3). A determinação dos níveis de clorofila se aplica principalmente em estudos com adubação nitrogenada, por haver correlações positivas entre os teores de clorofila e a concentração de nitrogênio nas folhas, devido ao papel do nitrogênio na síntese de clorofila (DEBAEKE et al., 2006) conforme já observado em diversas culturas (FERREIRA et al., 2006; VIANA\&KIEHL, 2010), entretanto, Gil et al. (2002) constataram diferenças nos teores foliares de clorofila em função da interferência da arquitetura foliar e do arranjo do dossel, tais achados, divergem dos resultados obtidos neste estudo. A fitomassa seca de plantas de soja foi influenciada pelos tratamentos adotados, sendo aqueles compostos pela semeadura convencional associada às populações de 120 e 160 mil plantas ha ${ }^{-1}$ os que apresentaram maior acúmulo de fitomassa diferindo estatisticamente dos demais tratamentos (Tabela 3). 
Tabela 3. Valores médios para as variáveis analisadas em pleno florescimento da soja (M-soy 9144 RR), em função dos tratamentos testados, Currais-PI, Brasil, safra 2011/2012.

\begin{tabular}{cccccc}
\hline \multirow{2}{*}{ Tratamentos } & Clorofila $^{\text {ns }}$ & Clorofila $^{\text {ns }}$ & Clorofila $^{\text {ns }}$ & $\begin{array}{c}\text { Fitomassa } \\
\text { seca }^{*}\end{array}$ & $\begin{array}{c}\text { Altura de } \\
\text { plantas }^{* *}\end{array}$ \\
\cline { 2 - 5 } & $\mathrm{b}$ & $\mathrm{a}$ & total & $\left(\mathrm{g} \mathrm{planta}^{-1}\right)$ & $(\mathrm{cm})$ \\
\hline T1 & 12,09 & 39,26 & 51,35 & $128,06 \mathrm{a}$ & $78,50 \mathrm{c}$ \\
T2 & 13,13 & 41,20 & 54,33 & $128,76 \mathrm{a}$ & $90,66 \mathrm{~b}$ \\
T3 & 12,78 & 41,50 & 54,28 & $77,30 \mathrm{~b}$ & $93,00 \mathrm{~b}$ \\
T4 & 12,05 & 40,14 & 52,19 & $71,93 \mathrm{~b}$ & $101,33 \mathrm{a}$ \\
T5 & 12,18 & 40,72 & 52,90 & $90,30 \mathrm{~b}$ & $100,66 \mathrm{a}$ \\
T6 & 12,67 & 40,23 & 52,90 & $86,33 \mathrm{~b}$ & $100,33 \mathrm{a}$ \\
T7 & 13,15 & 41,05 & 54,20 & $72,80 \mathrm{~b}$ & $99,00 \mathrm{a}$ \\
T8 & 12,56 & 41,15 & 53,71 & $80,66 \mathrm{~b}$ & $99,66 \mathrm{a}$ \\
\hline CV \% & 3,91 & 3,90 & 2,90 & 15,85 & 2,20 \\
\hline ** e * significativo a 1 e 5\% pelo teste F; ns: não significativo pelo teste F. Médias seguidas pela mesma letra na coluna não \\
diferem entre si a 5\% de probabilidade pelo teste de Scott-Knott
\end{tabular}

Estes resultados corroboram em parte com os obtidos por Watanabe et al. (2005) onde elevadas densidades de plantas de soja (400 mil plantas $\mathrm{ha}^{-1}$ ) resultaram em menor fitomassa quando comparada à menor densidade (200 mil plantas $\mathrm{ha}^{-1}$ ). A maior fitomassa nas menores densidades de plantas em sistema de plantio convencional pode estar relacionada com o aumento na taxa fotossintética, proporcionado pela maior intensidade na interceptação de luz pelo dossel, em razão do espaço disponível entre plantas (VENTIMIGLIA et al., 1999) o que também provoca maior ramificação da cultura.

Ao adotar o sistema cruzado de semeadura verificaram-se plantas com maior desenvolvimento em altura, da mesma forma que no plantio convencional, porém com maior densidade de plantas (240 mil plantas $\mathrm{ha}^{-1}$ ) (Tabela 3). Os resultados do presente estudo corroboram aos obtidos por Tourino et al. (2002); Mauad et al. (2010); Lima et al. (2012). Maiores densidades de semeadura resultaram em maior altura de plantas, possivelmente em razão da menor quantidade de energia luminosa e radiação fotossinteticamente ativa presente no dossel. A quantidade da luz recebida pelas plantas por meio dos fotoreceptores afeta o padrão de crescimento das plantas, portanto em baixa quantidade da luz as plantas de soja tendem a exibir alto crescimento em altura, a fim de absorver esses recursos, além de emitir menor quantidade de ramos (BOARD, 2000).

A altura de inserção do primeiro legume foi influenciada pela densidade de plantas, sendo as densidades maiores que 280 mil plantas $\mathrm{ha}^{-1}$ semeadas em sistema 


\section{CARACTERÍSTICAS AGRONÔMICAS E PRODUTIVAS DA SOJA CULTIVADA EM PLANTIO \\ CONVENCIONAL E CRUZADO}

cruzado, aquelas que apresentaram maiores valores para esse parâmetro (Tabela 4). O aumento na altura de inserção do primeiro legume com o aumento da densidade de plantas foi verificado por Mauad et al. (2010) e Watanabe et al. (2005). Uma possível explicação para a maior altura de inserção do primeiro legume, nas plantas em elevadas densidades, pode estar relacionada à possível modificação morfofísica nas plantas em função destas apresentarem maior. Tal característica apresenta elevada importância, pois determina a regulagem da altura da barra de corte da colhedora, visando obter a máxima eficiência durante esse processo, que de acordo com Sediyama et al. (2005), para que não haja perda na colheita pela barra de corte, a altura mínima do primeiro legume deve ser de 10 a $12 \mathrm{~cm}$, em solos de topografia plana e de $15 \mathrm{~cm}$, em terrenos mais inclinados.

$\mathrm{O}$ número de legumes por planta decresceu em populações superiores a 160 mil plantas $\mathrm{ha}^{-1}$, o que se intensificou com a adoção da semeadura cruzada (Tabela 4). Tais resultados corroboram aos obtidos por Tourino et al., (2002) que variaram as densidades populacionais no cultivo da soja; no entanto, discordam dos obtidos por Lima et al. (2012) que não verificaram diferença entre as populações utilizadas, mas verificaram diferenças entre os sistemas de semeadura, onde a semeadura no sistema cruzado apresentou menor número de legumes por planta.

Tabela 4. Valores médios para as variáveis produtivas da soja (M-soy $9144 \mathrm{RR}$ ), em função dos tratamentos testados, Currais-PI, Brasil, safra 2011/2012.

\begin{tabular}{cccccc}
\hline Tratamentos & $\begin{array}{c}\text { Altura de } \\
\text { inserção }^{*}\end{array}$ & $\begin{array}{c}\text { Legume por } \\
\text { planta }^{* *}\end{array}$ & $\begin{array}{c}\text { Grãos por } \\
\text { legume }^{\text {ns }}\end{array}$ & $\begin{array}{c}\text { Massa de mil } \\
\text { grãos }^{* *}\end{array}$ & $\begin{array}{c}\text { Produtividade } \\
\text { de grãos }^{\text {ns }}\end{array}$ \\
\cline { 2 - 6 } (cm) & (uni.) & (uni.) & $(\mathrm{g})$ & (kg ha $\left.^{-1}\right)$ \\
\hline T1 & $18,41 \mathrm{~b}$ & $84,55 \mathrm{a}$ & 2,05 & $145,29 \mathrm{~b}$ & $3.060,66$ \\
T2 & $17,33 \mathrm{~b}$ & $82,66 \mathrm{a}$ & 2,06 & $146,02 \mathrm{~b}$ & $3.111,66$ \\
T3 & $18,58 \mathrm{~b}$ & $58,44 \mathrm{~b}$ & 2,01 & $147,11 \mathrm{~b}$ & $3.489,33$ \\
T4 & $18,55 \mathrm{~b}$ & $67,22 \mathrm{~b}$ & 2,06 & $145,15 \mathrm{~b}$ & $3.028,66$ \\
T5 & $18,66 \mathrm{~b}$ & $59,94 \mathrm{~b}$ & 2,11 & $149,81 \mathrm{a}$ & $3.241,00$ \\
T6 & $21,10 \mathrm{a}$ & $59,38 \mathrm{~b}$ & 2,08 & $150,21 \mathrm{a}$ & $3.263,00$ \\
T7 & $21,77 \mathrm{a}$ & $48,00 \mathrm{~b}$ & 2,21 & $148,38 \mathrm{a}$ & $3.400,33$ \\
T8 & $24,33 \mathrm{a}$ & $37,11 \mathrm{~b}$ & 2,06 & $151,38 \mathrm{a}$ & $3.016,00$ \\
\hline CV \% & 10,78 & 20,87 & 5,57 & 1,32 & 12,31 \\
\hline
\end{tabular}

** e * significativo a 1 e $5 \%$ pelo teste F; ns: não significativo pelo teste F. Médias seguidas pela mesma letra na coluna não diferem entre si a $5 \%$ de probabilidade pelo teste de Scott-Knott. 
Provavelmente, tais resultados podem estar relacionados ao fato de que nas maiores densidades de semeadura há maior competição por luz e menor disponibilidade de fotoassimilados, fazendo com que a planta diminua o número de ramificações e produza um número menor de nós, conforme relatado por Mauad et al. (2010). De acordo com estes mesmos autores são nos nós que se desenvolvem as gemas reprodutivas; dessa forma a redução no número de ramificações reduz o número de nós potenciais e, consequentemente, o número de legumes.

Não foram verificadas variações significativas no número de grãos por legume em função das densidades e sistemas de semeadura utilizado (Tabela 4). Tais resultados corroboram aos obtidos por Tourino et al. (2002) que não encontraram diferenças estatísticas nas diferentes densidades de semeadura, entretanto discordam dos resultados encontrados por Lima et al. (2012) que verificaram diferença nesse parâmetro para a densidade de plantas e o sistema de semeadura. De acordo com Mauad et al. (2010) o número total de grãos está relacionado com o número total de legumes, pois a redução no número total de legumes afeta diretamente o número de grãos por legumes, embora isso não tenha ocorrido no presente estudo.

A massa de mil grãos foi influenciada pelas densidades de plantas nos sistemas de semeadura convencional e cruzada. Maiores valores foram verificados no modo de semeadura cruzado, independentemente da densidade de semeadura (Tabela 4). Os resultados para a massa de grãos em função da densidade de semeadura são contraditórios na literatura, uma vez que Heiffig et al. (2006) e Mauad et al. (2010) não observaram efeito significativo, enquanto, Peixoto et al. (2000) e Tourino et al. (2002) observaram aumento para essa variável em função do aumento da densidade de semeadura. Da mesma forma Lima et al. (2012) relataram resultados semelhantes; entretanto, quando compararam o sistema convencional de semeadura e o cruzado não verificaram diferenças estatísticas.

A produtividade da soja não foi influenciada pelos tratamentos compostos pelas densidades em modo de semeadura convencional e cruzado (Tabela 4). Freitas et al. (2010) também verificaram que o aumento da densidade de semeadura não proporcionou maiores rendimentos para a cultura da soja, constatação feita somente para a semeadura em linhas não cruzadas. Entretanto, Lima et al. (2012) verificaram 


\section{CARACTERÍSTICAS AGRONÔMICAS E PRODUTIVAS DA SOJA CULTIVADA EM PLANTIO \\ CONVENCIONAL E CRUZADO}

diferenças nos sistemas de semeadura (convencional e cruzado) assim como nas densidades, observando superioridade da menor densidade e do sistema de semeadura cruzado. Dessa forma, a maior densidade de semeadura não deve ser indicada nessa situação nem mesmo no sistema cruzado, porque embora gere maior altura de plantas e massa de mil grãos, isso não se traduz em produtividade de grãos, além do que, resulta em maiores custos operacionais de sementes, abastecimento da semeadora e tempo de semeadura.

\section{CONCLUSÕES}

A altura e a inserção do primeiro legume em plantas de soja são maiores com o aumento do número de plantas na linha; entretanto, a fitomassa seca de plantas foi maior nas menores densidades. As diferentes densidades de semeadura no sistema cruzado promoveram maior massa de mil grãos, embora isso não tenha se refletido em maior produtividade, apenas uma compensação do menor número de legumes por planta.

\section{REFERÊNCIAS}

ARGENTA, G.; SILVA, P.R.F.; SANGOI, L. 2001. Arranjo de plantas em milho: análise do estado-da-arte. Ciência Rural, Santa Maria, v.31, n.6, p.1075-1084.
BOARD, J. 2000. Light interception efficiency and light quality affect yield compensation of soybean at low plant populations. Crop Science, Madison, v.40, n.5, p.1285-1294.

CONAB - Companhia Nacional Abastecimento 2014. Acompanhamento da Safra Brasileira de Grãos 2013/14, 10 Levantamento, Ago. 2014. Brasília, CONAB, $87 \mathrm{p}$.

CULTIVAR. 2010. Produtividade máxima. Revista Cultivar - Grandes Culturas, Pelotas, Ano12, n.136, p.34.

DEBAEKE, P.; ROUET, P.; JUSTES, E. 2006. Relationship between the normalized SPAD index and the nitrogen nutrition index: application to durum wheat. Journal of Plant Nutrition, New York, v.29, n.1, p.75-92.

FERREIRA, D.F. 2011. SISVAR: a computer statiscal analysis system. Ciência e Agrotecnologia, Lavras, v.35, n.6, p.1039-1042.

FERREIRA, M.M.M.; FERREIRA, G.B.; FONTES, P.C.R.; DANTAS, J.P. 2006. Índice SPAD e teor de clorofila no limbo foliar do tomateiro em função de doses de nitrogênio e da adubação orgânica, em duas épocas de cultivo. Revista Ceres, Viçosa, v.53, n.305, p.83-92.

FREITAS, M.C.M.; HAMAWAKI, O.T.; BUENO, M.R.; MARQUES, M.C. 2010. Época de semeadura e densidade populacional de linhagens de soja UFU de ciclo semitardio. Bioscience Journal, Uberlândia, v.26, n.5, p.698-708.

GIL, P.T.; CEZAR, P.R.F.; CECON, P.R.; FERREIRA, F.A. 2002. Índice SPAD para o diagnóstico do estado de nitrogênio e para o prognóstico da produtividade da batata. Horticultura Brasileira, Brasília, v.20, n.4, p.611-615. 
HEIFFIG, L.S.; CÂMARA, G.M.S.; MARQUES, L.A.; PEDROSO, D.B.; PIEDADE, S.M.S. 2006. Fechamento e índice de área foliar na cultura da soja em diferentes arranjos espaciais. Bragantia, Campina, v.65, n.2, p.285-295.

LIMA, S.F.; ALVAREZ, R.C.F.; THEODORO, G.F.; BAVARESCO, M.; SILVA, K.S.2012. Efeito da semeadura em linhas cruzadas sobre a produtividade de grãos e a severidade da ferrugem asiática da soja. Bioscience Journal, Uberlândia, v.28, n.6, p.954-962.

MAUAD, M.; SILVA, T.L.B., ALMEIDA NETO, A.I.; ABREU, V.G. 2010. Influência da densidade de semeadura sobre características agronômicas na cultura da soja. Revista Agrarian, Dourados, v.3, n.9, p.175-181.

PEIXOTO, C.P.; CÂMARA, G.M.S.; MARTINS, M.C.; MARCHIORI, L.F.S.; GUERZONI, R.A.; MATTIAZZI, P. 2000. Épocas de semeadura e densidade de plantas de soja: I. Componentes da produção e rendimento de grãos. Scientia Agrícola, Piracicaba, v.57, n.1, p.89-96.

PETTER, F.A.; SILVA, J.A.; PACHECO, L.P.; ALMEIDA, F.A.; ALCÂNTARA NETO, F., ZUFFO, A.M.; LIMA, L.B. 2012. Desempenho agronômico da soja a doses e épocas de aplicação de potássio no cerrado piauiense. Revista de Ciências Agrárias, Belém, v.55, n.3, p.190-196.

PROCÓPIO, S.O., BALBINOT JUNIOR, A.A., DEBIASI, H., FRANCHIN, J.C.; PANISON, F. 2013. Plantio cruzado na cultura da soja utilizando uma cultivar de hábito de crescimento indeterminado. Revista de Ciências Agrárias, Belém, v.56, n.4, p.319-325.

RAMBO, L.; COSTA, J.A.; PIRES, J.L.F.; PARCIANELLO, G.; FERREIRA, F.G. 2003. Rendimento de grãos da soja em função do arranjo de plantas. Ciência Rural, Santa Maria, v.33, n.3, p.405-411.

SEDIYAMA, T.; TEIXEIRA, R.C.; REIS, M.S. 2005. Melhoramento da soja. In: Borém, A. (Ed.) - Melhoramento de Espécies Cultivadas. 2.ed. Viçosa, UFV, p. 553-603.

TOURINO, M.C.C.; REZENDE, P.M.; SALVADOR, N. 2002. Espaçamento, densidade e uniformidade de semeadura na produtividade e características agronômicas da soja. Pesquisa Agropecuária Brasileira, Brasília, v.37, n.8, p.1071-1077.

VENTIMIGLIA, L.A.; COSTA, J.A.; THOMAS, A.L.; PIRES, J.L.F. 1999. Potencial de rendimento da soja em razão da disponibilidade de fósforo no solo e dos espaçamentos. Pesquisa Agropecuária Brasileira, Brasília, v.34, n.2, p.195-199.

VIANA, E.M.; KIEHL, J.C. 2010. Doses de nitrogênio e potássio no crescimento do trigo. Bragantia, Campinas, v.69, n.4, p.975-982.

WATANABE, R.T.; FIORETTO, R.A.; FONSECA, I.B.; SEIFERT, A.L.; SANTIAGO, D.C.; CRESTE, J.E.; HARADA, A.; CUCOLOTTO, M. 2005. Produtividade da cultura de soja em função da densidade populacional e da porcentagem de cátions ( $\mathrm{Ca}, \mathrm{Mg}$ e $\mathrm{K}$ ) no complexo sortivo do solo. Semina: Ciências Agrárias, Londrina, v.26, n.4, p.477-484.

Recebido em: 5/9/2014 Aceito para publicação em: 27/3/2016 